\title{
Technical aspects of nasal cavity surgery through the Le Fort I down-fracture approach: An otolaryngologist's point of view based on 90 patients' experience
}

\author{
Monika Morawska-Kochman ${ }^{1, A-F}$, Kamil Nelke ${ }^{2,3, B-D}$, Jan Nienartowicz ${ }^{4, B, E, F}$, Wojciech Pawlak ${ }^{4, A, C, F}$, Marek Bochnia ${ }^{1, A, C, E}$ \\ ${ }^{1}$ Department of Clinic Otolaryngology, Head and Neck Surgery, Faculty of Postgraduate Medical Training, Wroclaw Medical University, Poland \\ ${ }^{2}$ Department of Maxillofacial Surgery, $4^{\text {th }}$ Military Hospital, Wrocław, Poland \\ ${ }^{3}$ Department of Maxillofacial Surgery, University Teaching Hospital, Wrocław, Poland \\ ${ }^{4}$ Department of Maxillofacial Surgery, Faculty of Dentistry, Wroclaw Medical University, Poland \\ A - research concept and design; $\mathrm{B}$ - collection and/or assembly of data; $\mathrm{C}$ - data analysis and interpretation; \\ $D$ - writing the article; $E$ - critical revision of the article; $F$ - final approval of the article
}

Address for correspondence

\section{Kamil Nelke}

E-mail:kamil.nelke@gmail.com

\section{Funding sources}

None declared

\section{Conflict of interest}

None declared

\section{Received on May 14, 2017}

Reviewed on June 20, 2017

Accepted on November 22, 2017

Published online on August 7, 2018

\section{Cite as}

Morawska-Kochman M, Nelke K, Nienartowicz J, Pawlak W, Bochnia M. Technical aspects of nasal cavity surgery through the Le Fort I down-fracture approach: An otolaryngologist's point of view based on 90 patients' experience. Adv Clin Exp Med. 2019;28(2):203-210. doi:10.17219/acem/80746

DOI

10.17219/acem/80746

\section{Copyright}

Copyright by Author(s)

This is an article distributed under the terms of the Creative Commons Attribution Non-Commercial License (http://creativecommons.org/licenses/by-nc-nd/4.0/)

\begin{abstract}
Background. The downfracture access to septo- and turbinoplasty during maxillary osteotomy may be recommended in many cases. One or both of these laryngological interventions may be necessary when, after the patient's clinical evaluation, either an impaired function of nasal breathing or a deviated septum are present. The main postsurgical risk of the procedure is the destabilization of the cartilaginous septum position and its relation to adjacent anatomical structures, a change in the shape of the nose and the presence of a supratip break.
\end{abstract}

Objectives. In this paper, the authors present their own experience in intranasal procedures, the relevant surgical techniques and possible complications, based on their own clinical findings and on a literature review.

Material and methods. The general aim of the study was to describe the key points and differences between septo- and turbinoplasty performed classically and during Le Fort l osteotomy based on 90 orthognathic surgery patient cases. The procedures have been evaluated and compared regarding their advantages and disadvantages.

Results. Intraoperative downfracture of the maxilla facilitates the performance of various subsequent procedures in the regions of the nasal cavities and sinuses. Due to a very convenient access to the nasal cavities, it is possible to perform septo- or turbinoplasty in patients with nasal airway breathing problems, a deviated septum, and in others.

Conclusions. A combined effort of an otolaryngologist and a maxillofacial team improves the overall nasal breathing with a limited amount of complications. Endoscopy with low-dose computed tomography (CT) is a valuable diagnostic tool for measuring any breathing improvements in nasal capacity. Objective patient nasal breathing problems should be always investigated.

Key words: nasal septum, orthognathic surgery, maxillary osteotomy, intranasal procedure, septoplasty 


\section{Introduction}

The main aim of orthognathic surgery is not only focused on the improvement of facial esthetics, but also on the quality of breathing. Along with achieving proper jaw alignment, surgery may lead to an improvement in the patient's speech, swallowing, breathing, sleeping, and other functions. There are specific conditions, such as sleep apnea, that can be treated with advancement or segmental jaw movement. Additional procedures performed during jaw surgery can also include corrective chin surgery, rhino-, septo- or turbinoplasty, temporomandibular joint surgery, cheek implant insertion, tissue augmentation, and more. The intranasal approach after maxillary downfracture is a known method of access to both nasal cavities and sinuses that is well-described in the literature. ${ }^{1,2}$ The indications and contraindications for this approach, and the usage of this technique are still under dispute worldwide.

Preoperative evaluation and measurement of the patient's quality of nasal airway breathing may include various diagnostic methods. They can be used along with the patient's medical history and a physical examination to evaluate the need for an additional surgery in the nasal cavities. To assess the patient's problems with nasal airway obstruction, some authors have used psychometric questionnaires, such as the Nasal Obstruction Symptom Evaluation (NOSE) scale. Studies seem to confirm the importance of the NOSE scale as an evaluation tool that may increase surgical indications for an additional nose surgery. ${ }^{3,4}$ Nonetheless, the method is only a subjective evaluation of nasal obstruction. Nowadays, computed tomography (CT) is the gold standard for facial skeletal evaluation. Other methods lag behind CT. ${ }^{5,6}$ Cephalometry performed as a non-routine examination, as well as other optional procedures - like video endoscopic photographic documentation of the nose and nasopharynx, rhinomanometry or acoustic rhinometry, nasal inspiratory peak flow, and visual analogue scales - are also used in the assessment of the efficiency of breathing through the nose. ${ }^{7,8}$

Le Fort I osteotomy is used for the correction of dentofacial deformities in the middle part of the facial skeleton. Indications for this osteotomy might include maxillary deficiency, hypoplasia or hyperplasia, gummy smile, or other types of dentofacial deformities. ${ }^{9-12}$ Surgical repositioning of the maxilla, particularly its advancement, may result in an improvement in nasal breathing. This is due to the increase in the volume of the nasal cavity and the size of the nasolabial angle, which improves nasal ventilation. ${ }^{8,12}$ Sometimes, to avoid functional problems in nasal breathing, an additional intervention is needed, particularly in patients with increased preoperative nasal airway resistance. In some of these patients, e.g., patients with a deviated nasal septum, their existing symptoms may be aggravated if such procedures are abandoned. Proper functioning of the upper airway has a considerable effect on the patient's quality of life. Improvement after orthognathic surgery combined with septo- or turbinoplasty applies not only to the nasal patency, but also to the sense of smell, sinus drainage, sleep comfort, effort, and daily fatigue tolerance. ${ }^{13}$

The majority of authors recommend providing the necessary concomitant septoplasty along with a reduction of the size of hypertrophic inferior nasal turbinates in the course of orthognathic surgery with Le Fort type osteotomy and the downfracture approach for exposure. ${ }^{10,14}$ These procedures are most often executed by maxillofacial surgeons, and rarely by ear, nose and throat (ENT) specialists. In the presented paper, the authors collected a team of maxillofacial and ENT surgeons that evaluated and operated on orthognathic patients together.

In the course of our collaboration, we noticed some differences depending on the specialization of the surgeon performing the procedure. These differences involved the approach to the problem of the impaired nasal airflow and the surgical techniques selected to improve it. The general aim of this study was to describe the key points and differences between septo- and turbinoplasty performed classically and during Le Fort I osteotomy. Our own clinical experience on the simultaneous septo- and turbinoplasty technique with the downfracture access will be presented. Furthermore, an additional objective was to focus on improving nasal breathing in treated patients.

\section{Ethics statement}

This paper required approval from an institutional committee, since the study is related directly with human care and treatment. The presented paper is in full compliance with and corresponds to the Helsinki Declaration.

\section{Material and methods}

A total of 90 patients' charts were reviewed. In the study, $54 \%$ of patients were male (males (M): $49,54.44 \%$; females (F): 41, 45.55\%). The average age of the patients was 26.6 years (range: 19-38 years). Qualification for nasal procedures was done after considering the medical history of anamneses, an endoscopic examination and evaluation of CT findings in particular. A total of 29 participants of the study group were diagnosed with bilateral decreased nasal patency, while 23 had permanent onesided nasal obstruction. Another 23 patients had periodic nasal obstruction episodes and 15 had never reported any sensations of nasal patency. We carried out 46 septoplasties and 44 turbinoplasties (19 bilateral and 25 unilateral) in the presented group (Table 1). STATISTICA software v. 17 (StatSoft Polska, Kraków, Poland) was used for t-test evaluation. All surgical and clinical data was gathered and analyzed with Statistical Package for the Social Sciences (SPSS) v. 17 software (SPSS Polska, Kraków, Poland) with 
Table 1. Detailed patient procedures

\begin{tabular}{|c|c|c|c|c|}
\hline $\begin{array}{l}\text { Procedure } \\
(n=100)\end{array}$ & \multicolumn{4}{|c|}{$\begin{array}{c}\text { Patient data } \\
\mathrm{n}=90(\mathrm{M}=49 ; \mathrm{F}=41) ; \mathrm{p}<0.05\end{array}$} \\
\hline $\begin{array}{l}\text { Septoplasty } \\
n=46 ; 100 \% ; p>0.05\end{array}$ & \multicolumn{2}{|c|}{$\begin{array}{c}M \\
n=27 \\
58.7 \% \\
p<0.05\end{array}$} & \multicolumn{2}{|c|}{$\begin{array}{c}F \\
n=19 \\
41.3 \% \\
p>0.05\end{array}$} \\
\hline & \multicolumn{2}{|c|}{ bilateral $(n=19)$} & \multicolumn{2}{|c|}{ unilateral $(\mathrm{n}=25)$} \\
\hline $\begin{array}{l}\text { Turbinoplasty } \\
n=44 ; 100 \% ; p<0.05\end{array}$ & $\begin{array}{c}M \\
n=7 \\
15.9 \% \\
p>0.05\end{array}$ & $\begin{array}{c}F \\
n=12 \\
27.28 \% \\
p<0.05\end{array}$ & $\begin{array}{c}M \\
n=15 \\
34.09 \% \\
p<0.05\end{array}$ & $\begin{array}{c}F \\
n=10 \\
22.73 \% \\
p>0.05\end{array}$ \\
\hline
\end{tabular}

M-males; F-females.

Table 2. Access points to the nasal septal framework

\section{Most common surgical approaches to the nasal septum}

Kilian incision (through the mucosa and perichondrium up to the septal cartilage)

Partial-transfixion incision (a vertical incision of the skin of the nasal vestibule) transfixion incision (an incision made at the caudal end of the septal cartilage); a subperichondrial dissection can be provided on 1 or both sides of the septum

external approach; an incision performed in the open approach that combines the incision on the level of the columella with the horizontal marginal incision along the greater alar cartilages the use of the $\chi^{2}$ test and the analysis of variance (ANOVA). Most data was focused on improved nasal breathing estimation in the patients undergoing surgery.

The surgical technique that we suggested was used in each case presented in this paper. In order to understand changes in nasal breathing, it is essential to understand the key points of this team-approach surgical technique. Proper preparation of the nasal mucosa is a very important aspect in every procedure regarding the nasal septum. In the classic technique of septoplasty, the nasal mucosa is first sprayed with a combination of $2 \%$ lidocaine and 1:100,000 epinephrine. Next, 5 min later, 2 pledges soaked in the same solution are inserted into each nasal cavity for $5 \mathrm{~min}$. After that, the mucosa of the septum is infiltrated on each side with $5 \mathrm{~mL}$ of $1 \%$ lidocaine and 1:100,000 epinephrine solution. The solution should be injected under the mucoperichondrium to elevate the mucosa. This should make the dissection much easier. In the case of exposure of the nasal septum by downfracture during orthognathic surgery, infiltration or local anesthesia are usually not applied. Two gauzes soaked with anticoagulant rinse (acidum tranexamicum) are placed into both nasal cavities while surgical burs are used and the frontal maxillary sinus walls are cut horizontally. The average time of gauze application is about $5 \mathrm{~min}$.

Injection through the nasal passages is particularly difficult on the side of the naso-tracheal intubation. In our opinion, topical anesthesia at least should be applied at the beginning of the procedure - infiltration of both the side wall and the septum of the intubation-free side - since access to the nasal septum will be much more difficult after the exposure of the inferior part of the septum and downfracture. Even a unilateral injection applied under the mucoperichondrium decreases the risk of laceration and injury of the mucosa of the septum and the oral cavity floor.
It also facilitates the following procedure. The most common access points to the nasal septum framework in the classic technique have been well-described (Table 2). ${ }^{15}$

Endonasal approaches to the nasal skeleton can be used for the primary treatment of traumatic injuries, and for secondary procedures, such as septorhinoplasty, but are useless in the Le Fort I downfracture procedures. The exposure of the septum after downfracture both facilitates and enforces a completely different surgical approach. We would like to distinguish our approach with a separate name: the downfracture approach.

During Le Fort I osteotomy from the sublabial approach, the anterior nasal spine is dissected, then a submucosal tunnel is made in the nasal floor; after that, the nasal crest is cut with a chisel. The nasal crest forms a groove for the reception of the septal framework. The inferior part of the quadrangular cartilage on the side of the nasal spine and the vomer in the posterior part are partially dissected. Usually, after chiseling above the bone groove (about $3 \mathrm{~mm}$ deep) and fracturing the vomer, the inferior part of the nasal septum is removed. Usually, its height is about $2-3 \mathrm{~mm}$, which corresponds to the depth of the groove. The remaining part of the nasal crest is removed and the groove is dredged up to the proper depth depending on the extent of the impaction or advancement (and on other combinations of surgical moves, such as rotation or extrusion) of the maxilla during the procedure, mostly in the area of the pyriform aperture. After a controlled surgical break of the maxilla, an open access to the nasal septum is gained, from its bony base upward - a larger access in the anterior part and a smaller one in the posterior part, as well as access to the turbinates and the nasal cavity floor. The shortcoming is the limited visibility in the middle and superior posterior part of the septum, and in the posterior nares (Fig. 1,2). 


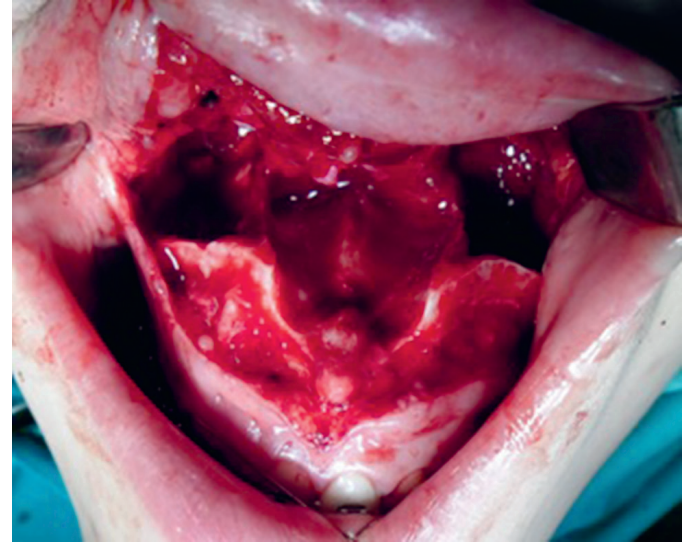

Fig. 1. Intranasal approach to the septum and conchae

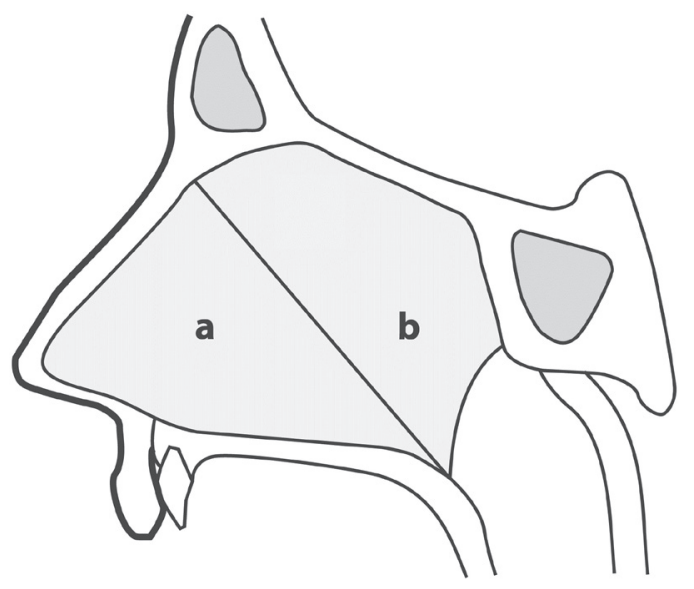

Fig. 2. Nasal septum projection with areas "a" and "b"

The next step of the procedure is the dissection of the mucoperichondrial and mucoperiosteal flaps, which facilitates the release and repositioning of deviated septal structures. Preparation of the mucoperiosteal flaps is usually easier in the posterior part of the septum. Using a Freer elevator in a sweeping motion, the surgeon is able to dissect the mucoperichondrium from the entire septal cartilage and septal bone (Fig. 3). This is typically performed on

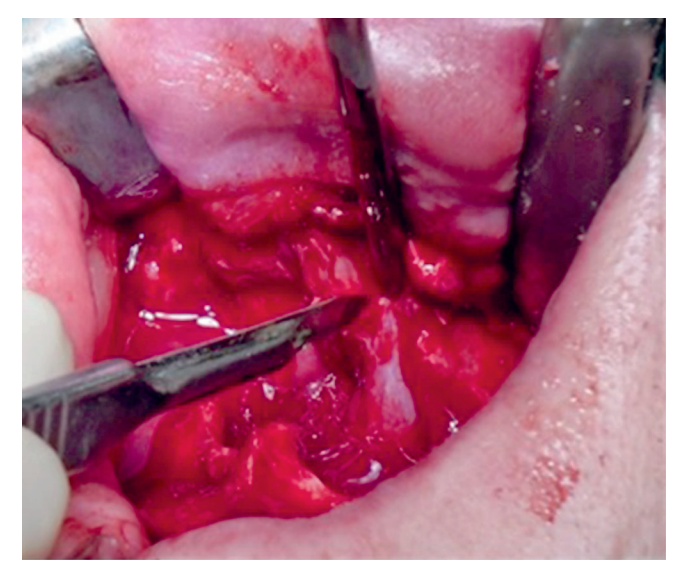

Fig. 3. Dissection of the mucoperichondrium from the entire septal cartilage and septal bone
1 side only in order to preserve blood supply to the septum. Sometimes, with a large area and complicated architecture of the deviation, unilateral dissection may be insufficient. In the discussed downfracture technique, the preparation is difficult, because the septum is mobile and unsupported, and the border between the mucoperichondrial layer, the mucoperiosteal layer, the cartilage, and the bone is poorly visible. A mass of connective tissue fibers, previously connecting the septal mucosa to the incisive bone, are cut while chiseling the bone groove, which complicates the situation even more. In order to protect the septal mucosa, it is often necessary to cut the superficial layer of fibers at the base of the septum with a scalpel. In our opinion, the initial dissection of the mucosa from the nasal cavity floor and the lower part of the septum, made under visual control before chiseling above the groove, may significantly facilitate further proceedings. This is because the inferior mucosal tunnel prepared at the beginning of the procedure is often injured and needs to be sutured at the end of the procedure. This kind of laceration also uncovers a subjacent part of the lower turbinate. If the surgeon is planning to perform a turbinoplasty and the whole mucosa is preserved, it should be cut parallel to the lower margin of the lower turbinate, as described by Posnick and Agnihotri (Fig. 1). ${ }^{14}$ It is possible to modify the single incision into a T-shaped cut in order to gain better access to the surface of the turbinates and to limit the risk of uncontrolled laceration of the mucosa (Fig. 2).

This stage of the operation is preferable for turbinoplasty or turbinectomy procedures. We prefer submucosal thermal ablation, which can be performed with a cautery unit. This technique, as opposed to a partial or complete turbinate resection, ensures the preservation of the nasal mucosa. In some cases, cauterization can be completed with a partial resection of the overgrown posterior parts of the inferior turbinates with the loop.

In the next step, the chondro-osseal junction of the quadrangular cartilage, the perpendicular plate and the vomer are dissected. After that, the deviated part of the chondro-osseal septal framework is removed, with particular care to spare as much of the patient's tissue as possible. Fixing the anterior-inferior septal cartilaginous strut to the maxillary anterior nasal spine with a 4-0 polydioxanone (PDS) suture (Johnson \& Johnson, Ethicon Inc., Bridgewater, USA) and the cartilage junction to the vertical part of the ethmoid bone is particularly important for the proper projection of the nose tip and for stable anchorage of the nasal septum. Failure in this element of the procedure may cause a rearward or bilateral shift of the nasal septum. We recommend controlling the position of the septum not only from the side of the maxilla, but also using a nasal speculum through the anterior nares on the side of the free nasal passage. This maneuver is particularly useful in the assessment of the necessary extent of the resection of the septal framework and of the patency of the inferior and middle nasal passage. At the end of the procedure, the 
mucosa of the nasal cavity floor is stitched with a single 4-0 polydioxanone (PDS) suture. Silastic septal splints are then applied to each of the mucoperichondrial planes with a running 4-0 nylon suture to stabilize the mucosal flap and to prevent septal hematoma or scare formation. ${ }^{2,16}$ It is more difficult to stitch the flaps and to place the splints in the nasal vestibule during orthognathic surgery than during the classic septoplasty. This is due to the intubation tube placed in one of the nose cavities. Limited visibility and placement of the naso-tracheal tube without adequate insight and careful septal splint suturing might lead to suturing or perforating the tube.

Our experience shows that the use of systemic steroids tends to be effective in the postoperative period to reduce mucosal edema. Patients receive intravenous steroids (dexamethasone, max $24 \mathrm{mg} /$ day) on the day of surgery and 1 day postoperatively. First, $8 \mathrm{mg}$ of dexamethasone is administered at the start of Le Fort I osteotomy and the $2^{\text {nd }}$ dose is administered up to $4-6 \mathrm{~h}$ after surgery. The last dose $(8 \mathrm{mg})$ is administered early in the morning on the $1^{\text {st }}$ day after surgery.

The nasal packing and septal splints are removed in the $1^{\text {st }}$ week after the operation. In order to minimize intranasal edema and crusting, patients are instructed to use an intranasal local vasoconstrictor agent (xylometazoline hydrochloride) 2-3 times per day in the $1^{\text {st }}$ week and a saline mist 4-6 times per day for 2-3 weeks after the operation. Each patient is evaluated postoperatively by craniofacial surgeons and otolaryngologists at weekly intervals for a total of 3 consultations.

\section{Results}

Bilateral turbinoplasty with simultaneous septoplasty were performed in 36 cases $(40 \%$; $<$ 0.05) (Table 1). Improvement in nasal breathing after routine endoscopic and CT evaluation was found in 78 patients $(86.7 \%$; $<<0.05)$. In 2 cases, nasal breathing was greatly impaired, as shown in Fig. 2, because of subluxation of the nasal septum in area " $a$ " and because of the presence of the nasal spine in the deviated area "b". No correlation between gender or age and nasal patency was noticed $(\mathrm{p}>0.05)$.

\section{Discussion}

Various techniques are quite often performed in addition to standard procedures in orthognathic surgery. ${ }^{17-20}$ Sarver and Rousso point out that rhinoplasty, submental liposuction, malar augmentation, lip lift and augmentation can easily be performed simultaneously with Le Fort I downfracture. ${ }^{17} \mathrm{We}$ would like to highlight that rhinoplasty is the most common technique here. It is also quite important to note that orthognathic surgery performed together with rhinoplasty can greatly influence the upper airway system. The authors of the studies on concurrent orthognathic and septo- and turbinoplasty procedures that were available for this review were mostly maxillofacial surgeons. ${ }^{7,13,21,22}$ Most of them particularly recommend such proceedings in patients with pre-existing nasal patency disorders. ${ }^{7,13,14}$ A study performed by Haarmann et al. in order to evaluate changes in nasal airways after Le Fort I osteotomy and functional rhinosurgery confirms a significant improvement in breathing in the entire study group. ${ }^{7}$ The authors point out that during the impaction of the maxilla, additional rhinosurgery should always be performed. Waite et al. performed 22 septorhinoplasties simultaneously during orthognathic surgery. ${ }^{18}$ No significant differences were noticed in either Le Fort I procedure or isolated sagittal split osteotomies of the mandible, and their influence on septorhinoplasties. Unlike the previously cited authors, Williams et al. examined the nasal airway function with a quality-of-life survey instrument in patients after Le Fort I osteotomy performed without any rhinosurgery. ${ }^{23}$ As a result of maxillary advancement, patients scored $>25$ points on the NOSE scale and reported a lack of nasal obstructive symptoms. In our opinion, this may have resulted from the different rules of case selection, as well as from different preparation and procedure techniques that diverge from standard laryngological procedures. The main differences include limited visibility into the nasal passages (nasal intubation), an imposed operational approach, the need to adjust the septoplasty and the resection of the lower part of the septum and lower turbinates to the anatomical conditions altered in the orthognathic procedure, and a lack of anterior nose packing after the procedure. There are 3 essential problems that should be considered when qualifying patients for orthognathic procedures: determination of the indications for simultaneous septo- or turbinoplasty, the resection mode of the cartilaginous part of the septum framework and the scope of volume decrease of the lower nasal turbinates.

Preliminary psychological assessment seems to be necessary not only regarding the orthognathic procedure, but also the septoplasty procedure, which is due to the arduousness of the postoperative period. Such discomfort is mostly due to the necessary application of septal splints that fix the septum within the median line and prompt a temporary nasal blockage. The recent review of the literature made by Tang and Kacker suggests that many types of septal splints are used worldwide; however, the usage of improved thinner splints might lead to an improvement in the mucosal status with decreased postoperative pain and discomfort. ${ }^{24}$ They can be used as an effective alternative to nasal packing after septoplasty. ${ }^{25} \mathrm{We}$ would like to stress that nasal packing after septoplasty in Le Fort I osteotomy is not only unnecessary, but it also can be life-threatening, as it blocks the nose, while the mandible and the maxilla are immobilized by the intermaxillary ligature steel wires used to fix the intraoral jaw.

Qualification for the surgery is usually based on a subjective and objective assessment of the patient. So far, there 
have been no established criteria for patient qualification for the procedure, and Posnick et al. - among others - suggests that there is a need for such qualification. ${ }^{10,13,14}$ Many subjective methods may be used in the assessment of nasal patency (visual analogue scales and psychometric questionnaires) as well as objective methods (pressure flowmeter, acoustic rhinomanometry and fiberoscopy). ${ }^{7-10,26-28}$ In our opinion, problems with breathing through the nose which are revealed in the patient's medical history are the most important indication for any nasal procedure. If an additional examination does not lead to a conclusion of whether the surgeon should perform an additional nasal surgery, the NOSE scale evaluation with the patient's best interests should be taken into consideration. Also, additional questions about sleep position and the ability to breathe through the nose while sleeping on the back should be asked.

Fiberoscopy is an objective assessment that reveals anatomical changes in the nasal region both before and after the surgery. It is useful in diagnosing changes connected with a deviated septum, adhesions or perforations that may be overlooked during rhinoscopy. Moreover, it is a rather inexpensive and noninvasive examination performed under local anesthesia. ${ }^{9}$ It should be performed preoperatively in every patient with a nasal patency disorder. Only an abnormal result in fiberoscopy may be a possible indication for extending the diagnostics with rhinomanometry. ${ }^{8}$ Rhinomanometry is a useful, objective method of preoperative and postoperative assessment, though, next to the diagnostic imaging methods, it may only increase the costs of the preparation for the procedure. ${ }^{7,8,27}$ It may reveal a possible nasal patency obstruction, but does not diagnose its anatomical cause. Otolaryngologists rarely make use of diagnostic imaging when preparing patients for septo- and turbinoplasty. Additionally, many clinicians use special computer planning before orthognathic surgeries. In most cases, it is used to evaluate and calculate bone and soft tissue changes, and it also helps to evaluate the upper respiratory tract patency and size. ${ }^{29} \mathrm{We}$ would like to point out that the examination which provides a precise assessment is $\mathrm{CT}$ with preliminary mucosal decongestion of the nasal turbinates. Nasal decongestants, in both topical and oral forms, are some of the most effective drugs available for reducing congestion of the turbinate mucosa, but only on the day of examination. Another way to reduce congestion is to use topical steroids a few days before the day of examination. During the initial clinical assessment of patients, in the process of qualification for surgery, we first performed the anterior rhinoscopy without topical decongestants. Then, a topical decongestant (oxymetazoline) was applied and rhinoscopy of the nasal airway was performed. We noted the nasal septum shape, the state of the mucosa and the size of the turbinates. Nasal endoscopy and CT not only facilitate imaging data collection and proper qualification for the procedure, but they also set the grounds for doctor-patient communication in order to explain the necessity of the procedure and the evaluation of its effects. At the qualification interview, the patient should always be informed about possible complications that may result from an extended orthognathic procedure, particularly with septoplasty. ${ }^{8}$

Another key technical problem is the extent of resection of the septal cartilage. This problem does not exist when the procedure is performed by a laryngologist in the classical manner. But when septoplasty is performed during orthognathic surgery, the extent of the resection of the inferior part of the septum should be taken into consideration in relation to dredging up the nasal cavity floor, widening the pyriform aperture and reducing the nasal spine, performed in order to reduce gummy smile. Those aspects of the procedure require the surgeon's close attention. In the case of orthognathic procedures, the proportions are altered and a mismatch may occur between the height of the septum that is mobilized at its entire length and the new dimensions of the advanced maxilla. It is important to try to resect the cartilage as sparingly as possible, as it can be reinserted after processing its shape and adjusting its dimensions to the new anatomical conditions. Laryngologists take care to preserve as much cartilaginous tissue as possible, particularly in the front part, in the nasal vestibule. Maxillofacial surgeons mostly pay attention to the shortening of the cartilaginous part of the septum, so after closing the edges of the bones, it rests "comfortably" in the groove made in the median line. When the remaining fragment is too high, the cartilage may dislocate sideways, narrowing the light of the nasal passages. In some cases, it might also increase the nasal supratip break (Fig. 4). A resection of the inferior part which is too large may induce - without correction of the deviation

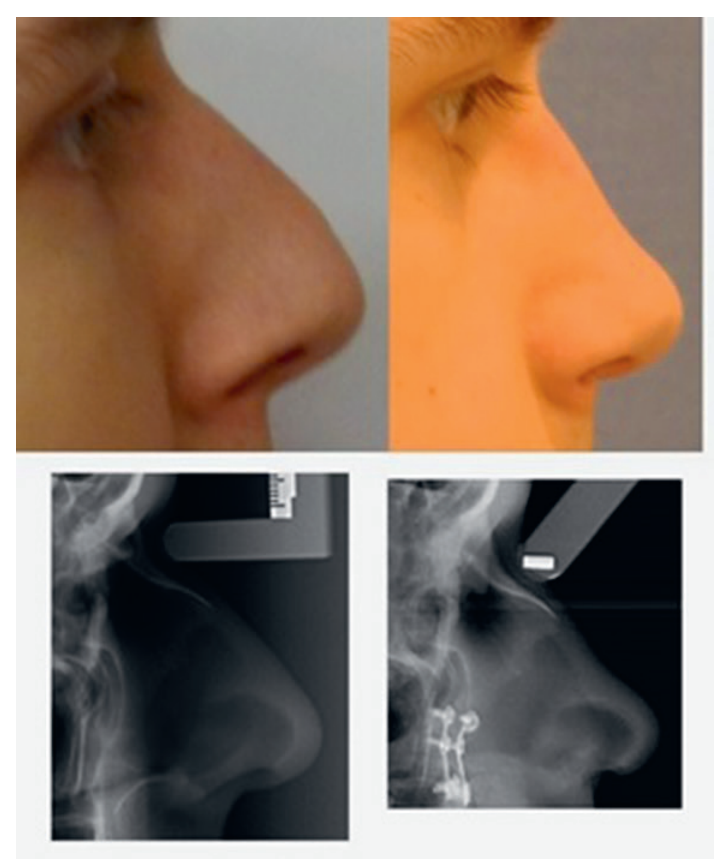

Fig. 4. Nasal tip and supra tip-notch projection before and after septoplasty and additional Le Fort I osteotomy 
- a transverse dislocation of the free fragment of the cartilage, which may block the nasal airways and decrease its patency after the procedure. This problem only concerns the flexible part of the septum - the cartilage. The rigid, bony part of the septum imposes the proper height by itself. Depending on the extent of the resection, a significant change in the shape of the nose may occur (into a saddle shape with an uplifted or dropped nose tip, a nasal hump, and a change in the shape of the nostrils). ${ }^{22}$ In our opinion, it is useful to jointly adjust the extent of the resection during the procedure, based on several fittings after the impaction of the maxilla.

Another problem is the approach to the surgery of the inferior nasal turbinates. The pathology of the turbinates is inseparably connected with their hypertrophy. The turbinate on the side of the deviation is usually small and atrophic, while the one on the other side is hypertrophic. Only the obstructive hypertrophy may be an indication for turbinoplasty, not the edema of the mucosa of the turbinate. The excessive tissue should be assessed after decongestion of the mucosa, by both endoscopy and a radiological examination. On the other hand, mucosal edema occurs during orthognathic procedures despite the application of decongestants at the beginning of the procedure. It seems that this problem is not usually taken into consideration, and the procedure may be performed too radically or not radically enough.

The techniques of volume reduction of the lower turbinate include turbinate outfracture, resection (submucosal resection, partial resection, trimming of the turbinates and inferior turbinoplasty, reduction by a microdebrider, and laser vaporization), electrocautery, cryosurgery, or coablation. ${ }^{30}$ In the most commonly used resection technique, it is recommended to reduce the inferior turbinate by $2 / 3$ of the volume. ${ }^{14,21}$ However, turbinectomy performed along the lower edge of the turbinate may result in massive hemorrhage, the development of granulation tissue or necrosis of the exposed bone. Radical removal of the inferior turbinate tissue may also provoke symptoms of so-called "empty nose syndrome." As a result of extensive scar formation after the turbinate resection, the patient may not feel hot and cold stimuli properly, having the impression of obstruction, with a substantial width of the nasal cavity. Extensive scars also impair the physiological functions of the nasal mucosa (warming, humidification and air filtration) predisposing the patient to the formation of crusts and recurrent pharyngitis. ${ }^{15,30,31}$ Physical injury to the mucosa may also be caused by cryosurgery, thermal ablation or radiofrequency ablation. The submucosal resection of the inferior turbinate is worth recommending, because it preserves most of the mucosa and preserves mucosal functions. Moreover, this technique is less likely to cause atrophic rhinitis. A new technique using a microdebrider blade through a small incision shows great results in reducing the size of the inferior turbinates. ${ }^{31,32} \mathrm{We}$ recommend submucosal ablation, which can be performed by submucosal cautery - it reduces the turbinate tissue with minimal damage to the surface. Submucosal ablation can also be provided by a radiofrequency device. ${ }^{33}$ Our experience indicates that there was no significant hemorrhage after the procedure using this technique. Also, after the extended procedure, with the loop resection of the hypertrophic posterior part of the turbinate, no massive hemorrhage was observed. ${ }^{34}$

Other complications of septoplasty, besides hemorrhages, include perforation of the septum, which, according to Erbe et al., occurs in $15 \%$ of patients being simultaneously operated on. ${ }^{8}$ A hematoma or septal abscess, adhesions between the septal mucosa and turbinates, deterioration in the sense of smell, or leakage of cerebrospinal fluid are rarely observed. Patients with those complications are usually referred to otolaryngological departments. A full discussion about the treatment undertaken exceeds the scope of this study. The number of centers undertaking surgical treatment of craniofacial deformations is steadily growing. At the same time, the popularization of simultaneously performed orthognathic surgery and septoplasty with possible turbinoplasty can be observed. We also recommend that those 2 procedures should be performed jointly by maxillofacial surgeons and laryngologists (a postulate of Posnick and Agnihotri, among others). ${ }^{13}$ Exploiting the laryngologists' knowledge of the anatomy and physiology of the upper part of the respiratory tract is meant to translate into better postoperative results and a higher degree of patient satisfaction. However, even an experienced laryngologist may be surprised during the procedure, as there is a different surgical approach - the downfracture access - a different manner and size of the septal framework resection, the need to fix the cartilage after the procedure and the impossibility of applying a bilateral nasal package. A proper volume reduction of the lower turbinates in the altered anatomical conditions of the orthognathic procedure may also constitute a problem. Therefore, the experience exchange between the 2 teams seems to be essential for achieving the best results.

\section{References}

1. Posnick JC. Orthognathic Surgery: Principles and Practice of Orthognathic Surgery. St. Louis, MO: Elsevier Saunders; 2013:517.

2. Farrior RT, Farrior EH. Chapter 48: Special rhinoplasty techniques. In: Richardson M, Flint $\mathrm{P}$, Haughey B, et al. Cummings Otolaryngology - Head and Neck Surgery. $5^{\text {th }}$ ed. Philadelphia, PA: Mosby Elsevier; 2010:545-566.

3. Stewart MG, Smith TL, Weaver EM, et al. Outcomes after nasal septoplasty: Results from the Nasal Obstruction Septoplasty Effectiveness (NOSE) study. Otolaryngol Head Neck Surg. 2004;130(3):283-290.

4. Stewart MG, Witsell DL, Smith TL, Weaver EM, Yueh B, Hannley MT. Development and validation of the Nasal Obstruction Symptom Evaluation (NOSE) scale. Otolaryngol Head Neck Surg. 2004;130(2):157-163.

5. Seth V, Kamath P, Venkatesh MJ, Prasad R, Vishwanath F. Cone beam computed tomography: Third eye in diagnosis and treatment planning. Virtual Journal of Orthodontics. 2011;3:1-11.

6. Wheeler SM, Corey JP. Evaluation of upper airway obstruction - an ENT perspective. Pulm Pharmacol Ther. 2008;21(3):433-441. 
7. Haarmann S, Budihardja AS, Wolff KD, Wangerin K. Changes in acoustic airway profiles and nasal airway resistance after Le Fort I osteotomy and functional rhinosurgery: A prospective study. Int J Oral Maxillofac Surg. 2009;38(4):321-325.

8. Erbe M, Lehotay M, Göde U, Wigand ME, Neukam FW. Nasal airway changes after Le Fort I - impaction and advancement: Anatomical and functional findings. Int J Oral Maxillofac Surg. 2001;30(2):123-129.

9. Pingarrón ML, Arias Gallo LJ, López-Arcas JM, Chamorro Pons M, Cebrián Carretero JL, Burgueño García M. Fibroscopic findings in patients following maxillary osteotomies in orthognathic surgery. J Craniomaxillofac Surg. 2011;39(8):588-592.

10. Posnick JC, Fantuzzo J, Troost T. Simultaneous intranasal surgery at the time of Le Fort I downfracture. J Oral Maxillofac Surg. 2007;65(11): 2273-2281.

11. Epker BN, Turvey T, Fish LC. Indications for simultaneous mobilization of the maxilla and mandible for the correction of dentofacial deformities. Oral Surg Oral Med Oral Pathol. 1982;54(4):369-381.

12. Götzfried HF, Masing H. On the improvement of nasal breathing following mid-face osteotomies, and possible reasons for the phenomenon. J Maxillofac Surg. 1984;12(1):29-32.

13. Posnick JC, Agnihotri N. Consequences and management of nasal airway obstruction in the dentofacial deformity patient. Curr Opin Otolaryngol Head Neck Surg. 2010;18(4):323-331.

14. Posnick JC, Agnihotri N. Managing chronic nasal airway obstruction at the time of orthognathic surgery: A twofer. J Oral Maxillofac Surg. 2011;69(3):695-701.

15. Theissing J, Rettinger G, Werner JA. ENT - Head and Neck Surgery: Essential Procedures. Stuttgart-New York: Georg Thieme Verlag; 2010: 45-109.

16. Persichetti $P$, Toto $V$, Signoretti $M$, et al. The correction of nasal septal deviations in rhinoplasty. Annals of Oral \& Maxillofacial Surgery 2013;1:13.

17. Sarver DM, Rousso DR. Plastic surgery combined with orthodontic and orthognathic procedures. Am J Orthod Dentofacial Orthop. 2004;126(3):305-307.

18. Waite PM, Matukas VJ, Sarver DM. Simultaneous rhinoplasty and orthognathic surgery. Int J Oral Maxillofac Surg. 1988;17(5):298-302.

19. Nocini PF, Chiarini L, Bertossi D. Cosmetic procedures in orthognathic surgery. J Oral Maxillofac Surg. 2011;69(3):716-723.

20. Elsalanty ME, Genecov DG, Genecov JS. Functional and aesthetic endpoints in orthognathic surgery. J Craniofac Surg. 2007;18(4):725-733.
21. Movahed R, Morales-Ryan C, Allen WR, Warren S, Wolford LM. Outcome assessment of 603 cases of concomitant inferior turbinectomy and Le Fort I osteotomy. Proc (Bayl Univ Med Cent). 2013;26(4):376-381.

22. Mommaerts MY, Lippens F, Abeloos JVS, Neyt LF. Nasal profile changes after maxillary impaction and advancement surgery. J Oral Maxillofac Surg. 2000;58(5):470-475.

23. Williams BJD, Isom A, Filho JRL, O'Ryan FS. Nasal airway function after maxillary surgery: A prospective cohort study using the Nasal Obstruction Symptom Evaluation scale. J Oral Maxillofac Surg. 2013; 71(2):343-350.

24. Tang S, Kacker A. Should intranasal splints be used after nasal septal surgery? Laryngoscope. 2012;122(8):1647-1648.

25. Wadhera R, Zafar N, Gulati SP, Kalra V, Ghai A. Comparative study of intranasal septal splints and nasal packs in patients undergoing nasal septal surgery. Ear Nose Throat J. 2014;93(9):396-408.

26. Warren DW, Hershey HG, Turvey TA, Hinton VA, Hairfield WM. The nasal airway following maxillary expansion. Am J Orthod Dentofacial Orthop. 1987;91(2):111-116.

27. Kunkel $M$, Hochban W. The influence of maxillary osteotomy on nasal airway patency and geometry. Mund Kiefer Gesichtschir. 1997;1(4): 194-198.

28. Pourdanesh F, Sharifi R, Mohebbi A, Jamilian A. Effects of maxillary advancement and impaction on nasal airway function. Int J Oral Maxillofac Surg. 2012;41(11):1350-1352.

29. Iorio ML, Masden D, Blake CA, Baker SB. Presurgical planning and time efficiency in orthognathic surgery: The use of computer-assisted surgical simulation. Plast Reconstr Surg. 2011;128(3):179.

30. Rice DH, Kern EB, Marple BF, Mabry RL, Friedman WH. The turbinates in nasal and sinus surgery: A consensus statement. Ear Nose Throat J. 2003;82(2):82-84.

31. Nurse LA, Duncavage JA. Surgery of the inferior and middle turbinates. Otolaryngol Clin North Am. 2009;42(2):295-309.

32. Liu CM, Tan CD, Lee FP, Lin KN, Huang HM. Microdebrider-assisted versus radiofrequency-assisted inferior turbinoplasty. Laryngoscope. 2009;119(2):414-418.

33. Garzaro M, Pezzoli M, Landolfo V, Defilippi S, Giordano C, Pecorari G. Radiofrequency inferior turbinate reduction: Long-term olfactory and functional outcomes. Otolaryngol Head Neck Surg. 2012;146(1): 146-150.

34. Hwang SH, Kang JM, Cho JH, Kim BK. What is the relationship between the localization of maxillary fungal balls and intranasal anatomic variations? Clin Exp Otorhinolaryngol. 2012;5(4):213-217. 